\title{
Peningkatan Kemampuan Badan Amil Menggunakan Fitur E-Zakat Sebagai Media Penyaluran kepada Mustahiq
}

\author{
Muhamad Awiet Wiedanto Prasetyo ${ }^{\mathrm{a}, 1, *}$, Rizky Bangkit Bachtiar ${ }^{\mathrm{b}, 2}$, Indika Manggala Putra ${ }^{\mathrm{b}, 3}$, \\ Laely Candra Arviana ${ }^{b, 4}$ \\ ${ }^{\mathrm{a}, \mathrm{b}}$ Program Studi Sistem Informasi, Fakultas Ilmu Komputer, Universitas Amikom Purwokerto \\ ${ }^{1}$ mawp@amikompurwokerto.ac.id *; ${ }^{2}$ rizkybangkit13@gmail.com; ${ }^{3}$ impbarca046@ gmail.com; ${ }^{4}$ arviilaely@ gmail.com \\ * corresponding author
}

\section{ARTICLE INFO}

Article History

Received,06-11-2020

Revised,24-12-2020

Accepted,19-01-2021

Keywords

Kedunggede Village;

Zakat A-Fitrah;

E-Zakat

\section{ABSTRACT}

The distribution of zakat fitrah coincides on the 30th of Ramadhan Hijriyah as in Kedunggede Village. There are prolems in the process of zakat distribution, the results of the reports from each hamlet must be known and singed by the committee chairman of the village administration and then determine the nominal money and weight of rice distributed. The solution offered is to implement an application that has been made by adjusting the needs partners, with the E-Zakat feature. The flow service method starts from presenting the existing infrastructure in Kedunggede Village regarding the use of information technology the presenting the use of the E-Zakat feature. The conclusion of this Amikom Mitra Masyarakat activity is that when the village amil zakat practice the E-Zakat feature it gets a good response and the amil zakat provides a satisfactory assessment because it can provide realtime information so that the time efficiency is felt.

\section{PENDAHULUAN}

Desa Kedunggede secara letak geografis masuk Wilayah Kecamatan Lumbir dan berbatasan langsung dengan Wilayah Kabupaten Cilacap bagian barat atau lebih tepatnya Kecamatan Karangpucung. Desa Kedunggede memiliki dataran rendah di bagian tengah dan perbukitan disisi utara dan selatan, serta terdapat Sungai Ciaur yang membelah desa tersebut. Desa Kedunggede dapat diakses melalui jalan nasional yang menghubungkan Jawa Barat, Jawa Tengah dan Yogyakarta. Desa Kedunggede memiliki tiga dusun yang memiliki dua rukun warga setiap dusunnya dan memiliki total penduduk sekitar 6.273 jiwa. Masyarakat pada umumnya di Bulan Ramadhan meningkatkan ibadahnya seperti melaksanakan perintah-Nya yang bersifat sunnah seperti shalat tarawih, berbuka puasa dengan buah kurma dan melaksanakan perintah-Nya bersifat wajib seperti shalat lima waktu dan zakat fitrah [1]. Zakat fitrah bagi umat beragama Islam harus memberikan harta yang berupa makanan pokok kepada orang yang berhak menerimanya dan dikeluarkan pada Bulan Ramadhan sampai dengan sebelum Shalat Idul Fitri pada Bulan Syawal [2]. Zakat mempunyai peran penting dalam pemberdayaan ekonomi umat. Namun negara-negara dimana mayoritas penduduknya beragama Islam yang termasuk dalam kategori negara sedang berkembang masih berada pada posisis tingkat kemiskinan yang masih tinggi termasuk negara Indonesia [3]. Zakat merupakan salah satu dari Lima Rukun Islam yang tentunya wajib bagi seluruh umat Islam yang mampu menjalankannya, sebagai firman Allah Subhanallahu Wa Ta 'ala yang terdapat pada Q.S At-Taubah Ayat 103, "Ambilah dari harta mereka sedekah (zakat) untuk membersihkan mereka serta menghapuskan kesalahan mereka." Kemudian terdapat juga pada Q.S Al-Baqoroh Ayat 43, "Dan dirikanlah shalat, tunaikanlah zakat dan ruku'lah berserta orang-orang yang ruku'."

Perintah zakat selalu beriringan dengan perintah shalat, karena kedua perintah tersebut memiliki tujuan yang hampir sama yaitu perbaikan kualitas kehidupan masyarakat [4]. Zakat bertujuan membersihkan diri dari sifat rakus dan kikir [5]. Selain itu zakat juga mendorong manusia untuk mengembangkan sifat kedermawanan dan sensitivitas kesetiaan sosial. Demikian pula dengan shalat bertujuan menghindari kehidupan manusia dari kejahatan dan kerusakan. Hal ini menunjukkan bahwa zakat dan shalat mempunyai kedudukan yang erat dalam hal keutamaanya, 
dimana shalat dipandang seutama-utamanya ibadah bathiniyah begitu juga zakat dipandang seutama-utamanya ibadah amaliyah. Seperti pada Desa Kedunggede pembagian zakat fitrah bertepatan pada Tanggal 30 Ramadhan Hijriyah. Pemerintah desa memberikan himbauan kepada kepala dusun untuk mewajibkan setiap warganya dilibatkan sebagai panitia zakat fitrah agar proses penyaluran zakat fitrah berjalan dengan cepat. Kegiatan pertama yang dilakukan oleh panitia adalah pendataan warga yang berhak menerima seperti fakir, miskin, amil, mu'allaf, riqab, gharim, fi sabilillah dan ibnu sabil. Kemudian menentukan jenis zakat fitrah yang harus dikeluarkan berupa beras dalam hitungan kilogram dan sejumlah uang tunai. Panitia berada dimushola atau masjid yang bertugas untuk merekap besaran total beras dan uang tunai setelah menerima dari muzakki, kemudian panitia akan saling berkoordinasi dari setiap dusunnya. Setelah menerima secara keseluruhan akan dipotong sebagian untuk kegiatan operasional panitia, selebihnya akan disalurkan kepada mustahiq.

Terdapat permasalahan diproses penyaluran kepada mustahiq seperti hasil laporan dari setiap dusun harus diketahui dan ditanda tangani terlebih dahulu oleh ketua panitia yang ada di pusat pemerintahan desa (Dusun 2) dan selanjutnya menentukan nominal uang dan bobot beras yang harus disalurkan. Perjalanan dari Dusun 1 dan 3 yang menuju ke Dusun 2 secara letak geografis saling berjauhan dan akses jalannya bermaterial batu-batuan atau belum diaspal secara keseluruhan yang mengakibatkan terlambatnya pelaporan kepada ketua panitia yang berdampak pada terlambatnya penyaluran zakat. Dalam hal ini, tim pengabdian mempunyai Aplikasi Tuan Desa dengan fitur E-Zakat agar kedepannya panitia zakat fitrah tidak kesulitan menentukan total nominal uang dan bobot beras yang harus diterima oleh penerima zakat fitrah. Pengelolaan zakat fitrah dengan cara konvensional, sering muncul beberapa masalah yang dapat menghambat dalam pengelolaan zakat tersebut. Saat ini perkembangan berbasis mobile khususnya menggunakan sistem operasi android sangat pesat perkembangannya, karena banyak digunakan oleh berbagai kategori seperti anak hingga kategori lanjut usia. Maka diharapkan aplikasi pembagian zakat dapat dimanfaatkan secara maksimal oleh badan amil zakat Desa Kedunggede.

Penulis memiliki tujuan untuk mengatasi permasalahan diatas dengan mengimplementasikan aplikasi yang sudah dibuat guna menyesuaikan kebutuhan mitra, seperti didukungnya infrastruktur berupa jaringan seluler $4 \mathrm{G}$ yang memiliki kecepatan yang sangat cepat dan perangkat smartphone dengan sistem operasi android minimal versi lollipop yang mampu menjalankan Aplikasi Tuan Desa. Sebelum menggunakan Fitur E-Zakat terdapat username dan password yang dibedakan menjadi dua hak akses yaitu admin dan amil. Hak akses Amil terdapat fitur input yang digunakan oleh badan amil untuk melakukan pengisian nama dusun, total nominal uang, total bobot berat beras dan button konfirmasi yang akan dikirimkan ke admin digunakan untuk menentukan total nominal uang tunai dan bobot beras yang akan diterima oleh mustahiq. Seperti pada hak akses user, hak akses admin terdapat fitur penambahan user yang berisi identitas, username dan password. Selanjutnya terdapat fitur laporan setiap dusun yang berisi nama amil, nominal uang tunai dan bobot beras yang dizakatkan. Kemudian terdapat fitur untuk menentukan besaran yang akan digunakan oleh badan amil sebagai zakat fitrah dan fisabilillah (kasus ini hitungan \% dengan mengambil total nominal uang yang sudah dilaporkan kepada panitia).

\section{PELAKSAAAN DAN METODE}

Diawali dengan mempersiapkan tim pengabdian kepada masyarakat yang beranggotakan satu dosen sebagai ketua pelaksana dan dua mahasiswa dari berbeda angkatan sebagai anggota pelaksana. Tugas ketua adalah melakukan pengumpulan data dengan cara obervasi kegiatan dari proses pembentukan tim panitia zakat fitrah yang melibatkan Pemerintah Desa Kedunggede dan tokoh masyarakat Desa Kedunggede, selanjutnya panitia menentukan siapa yang menjadi ketua panitia dan tugas panitia yang lainnya, kemudian panitia menentukan besaran zakat fitrah berupa nominal uang dan besar bobot beras, pengumpulan zakat fitrah yang bertempatan di mushala setiap dusun, penyaluran zakat fitrah kepada mustahiq dan laporan akhir hasil kegiatan zakat fitrah. Pengumpulan data selanjutnya wawancara kepada panitia zakat fitrah, menanyakan seputar kendala apa saja yang terjadi selama proses zakat fitrah seperti terlambatnya penyampaian informasi, kesulitan untuk menghitung besaran yang akan diterima oleh mustahiq dan laporan hasil akhir kegiatan zakat fitrah. 
Setelah mendapatkan permasalahan, tim akan menganalisa kebutuhan yang diperlukan oleh mitra. Ketua tim bertugas menyusun proposal dan laporan akhir Amikom Mitra Masyarakat. Sedangkan anggota satu bertugas mempersiapkan aplikasi zakat fitrah yang sudah dibuat sebelumnya dan memastikan aplikasi tersebut dapat digunakan dengan baik. Anggota dua mempersiapkan apa saja yang akan dibutuhkan waktu pelatihan aplikasi zakat fitrah berlangsung seperti form presensi kehadiran presensi, materi pelatihan, meja, kursi, proyektor, koneksi internet dan jenis smartphone yang akan digunakan oleh peserta.

Selanjutnya tim melakukan kordinasi dengan mitra untuk menentukan tamu undangan seperti Kepala Desa Kedunggede, Ketua BPD Kedunggede dan Tokoh Masyarakat Desa Kedunggede. Kemudian mitra berkoordinasi dengan karang taruna untuk mendokumentasikan kegiatan pelatihan aplikasi zakat fitrah dan kordinasi dengan pemerintahan desa untuk memfasilitasi selama kegiatan. Kegiatan pelatihan aplikasi zakat dimulai dengan sambutan dari ketua tim Amikom Mitra Masyarakat, Ketua Panitia Zakat Fitrah dan Kepala Desa. Kemudian ada penyampaian materi seputar infrastruktur yang ada di Desa Kedunggede berupa didukungnya akses jaringan seluler yang sudah 4G, jaringan internet kabel fiber optic dan lainnya. Pada acara inti, ketua tim akan mempresentasikan fitur-fitur yang ada pada aplikasi zakat dan diikuti oleh para peserta pelatihan seperti kepala desa beserta stafnya, panitia zakat fitrah tahun sebelumnya dan perwakilan warga dari setiap dusun yang menjadi calon panitia zakat fitrah tahun sekarang yang didampingi oleh anggota tim. Setelah acara inti selesai, ada sesi tanya jawab dari para peserta sebelum penutupan acara kegiatan pelatihan aplikasi zakat fitrah

Setelah acara pelatihan dilaksanakan, maka tim akan mengevaluasi hasil kegiatan bersama mitra, kemudian ketua tim membuat laporan kegiatan Amikom Mitra Masyarakat dan jurnal pengabdian, anggota satu akan membuat dokumentasi dalam bentuk video yang didistribusikan melalui media sosial youtube dan sedangkan anggota dua membuat narasi yang nantinya akan di publish media massa cetak local.

\section{HASIL DAN PEMBAHASAN}

Kegiatan pengabdian kepada masyarakat yang dilakukan di Lingkungan Masjid Baitul Yamin dan Balai Desa Desa Kedunggede pada Tanggal 21 sampai dengan 23 Mei 2020 atau 28 sampai dengan 30 Ramahdan 1441 Hijriyah, dengan total peserta sebanyak 25 orang dari Badan Amil Zakat Desa Kedunggede. Diawali dengan ketua tim pengabdian memberikan sambutan kepada para peserta dan dilanjutkan dengan sambutan dari Ketua Badan Amil Zakat Fitrah dihari pertama pengabdian Tanggal 21 Mei 2020 atau 28 Ramadhan 1441 Hijriyah, kemudian dilanjutkan sosialisasi penggunaan aplikasi tuan desa dengan fitur zakat fitrah.

Fitur E-Zakat yang ada di Aplikasi Tuan Desa adalah fitur yang digunakan oleh badan amil zakat fitrah yang berada disetiap dusunnnya, untuk Desa Kedunggede terdapat dusun 1 hingga dusun 3. Hak Akses User sebagai badan amil hanya melakukan penginputan alamat dusun, total nominal uang dan total bobot beras dari muzzaki, sedangkan hak akses admin dapat melakukan penginputan layaknya hak akses user dan menerima hasil inputan dari setiap badan amil yang masuk ke menu laporan keseluruhan. Selain itu, admin bisa menentukan total mustahiq dan melihat hasil perhitungan yang akan diterima oleh mustahiq. Setelah acara sosialisasi selesai, tim pengabdian melakukan pendampingan selama dua hari terhadap badan amil zakat melakukan penginputan data muzzaki dan besaran zakat fitrah pada aplikasi. Kemudian di hari terakhir Tanggal 23 Mei 2020 atau 30 Ramadhan 1441 Hijriyah, tim pengabdian melakukan pendampingan terhadap badan amil zakat mengenai cara mengetahui total mustahiq, nominal uang dan bobot beras yang akan diterima oleh mustahiq. 


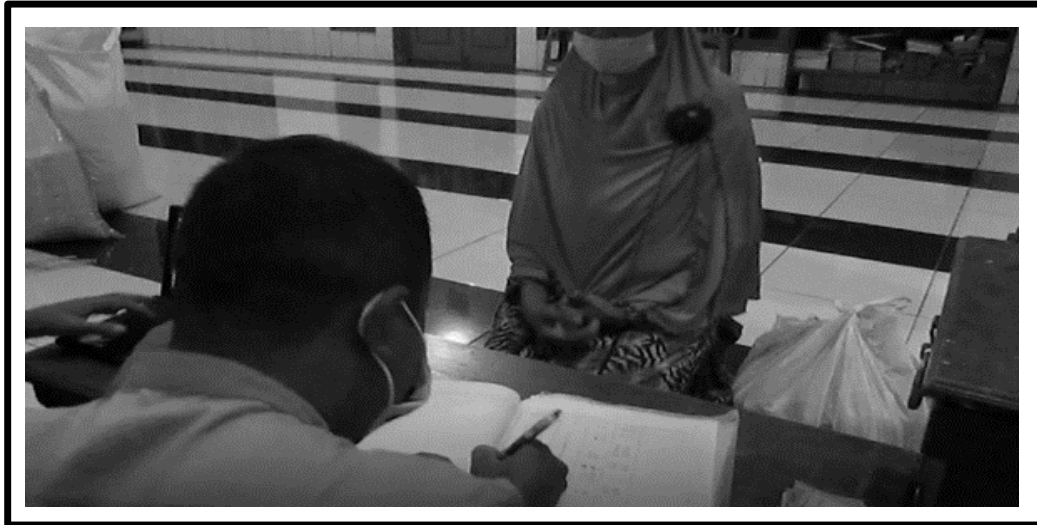

Gambar 1. Proses pencatatan

Gambar 1. Proses Pencatatan, menerangkan tentang badan amil mencatat identitas dari muzzaki seperti nama lengkap, alamat berdasarkan nama dusun dan alamat berdasarkan rukun tetanggan/rukun warga, kemudian badan amil menuliskan jenis zakat fitrah muzakki berdasarkan uang tunai atau beras dalam hitungan kilogram.

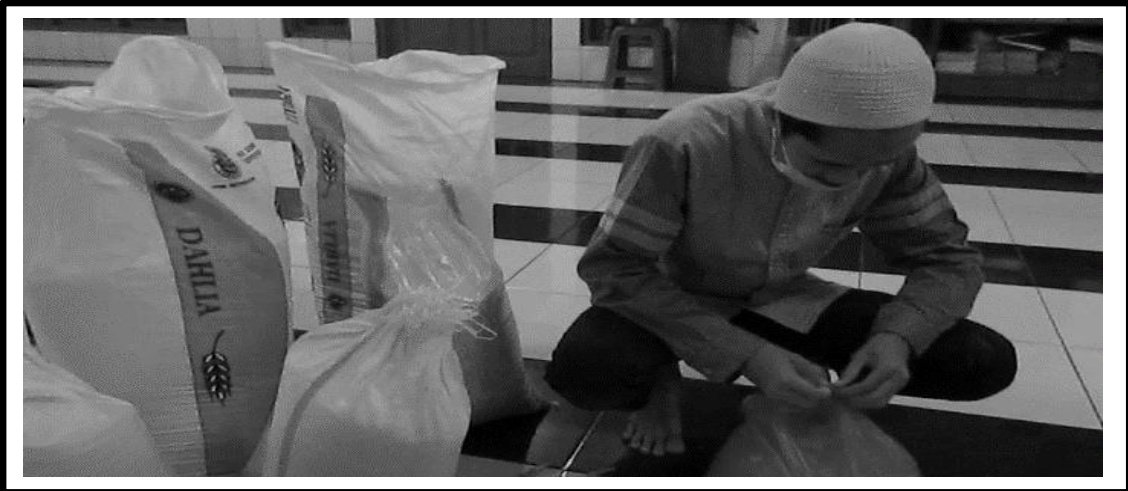

Gambar 2. Pengumpulan beras

Gambar 2. Pengumpulan Beras, menerangkan tentang badan amil melakukan pengumpulan beras yang diterima oleh muzzaki kedalam karung beras. Bobot beras yang harus diserahkan kepada badan amil minimal sebesar $2,5 \mathrm{Kg}$ beras setiap muzzaki namun apabila muzzaki ingin melebihi dari batas minimal diperbolehkan dari pihak badan amil.

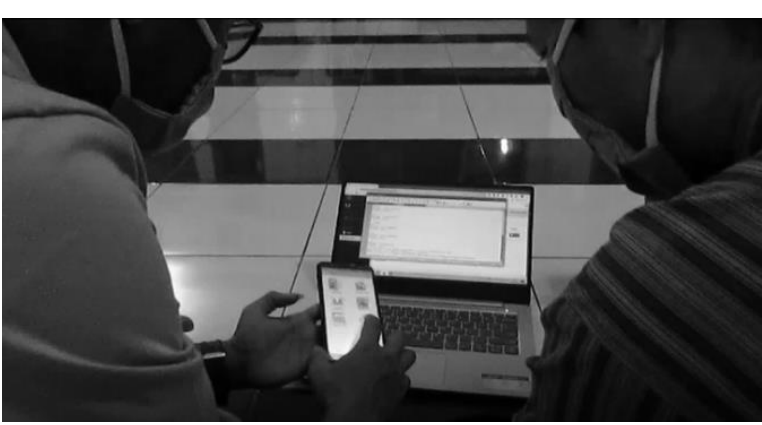

(a)

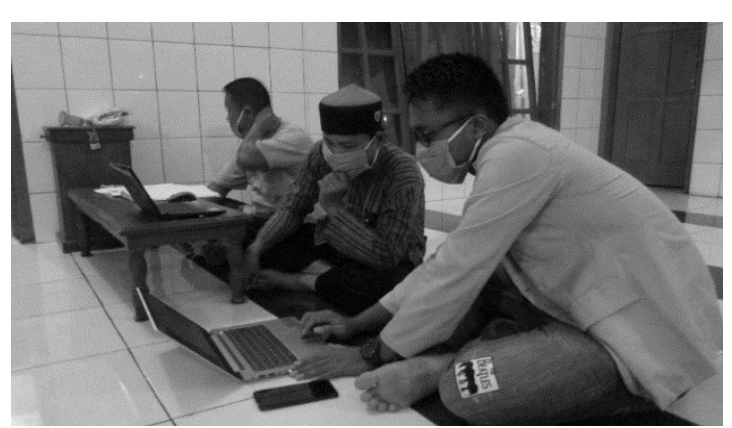

(b)

Gambar 3. Sosialisasi Penginputan Melalui Android (a) dan Melalui Web (b)

Berdasarkan Gambar 3. Sosialisasi Penginputan Melalui Android (a) dan Melalui Web (b). Menjelaskan terdapat form nama dusun yang bisa diisikan berdasarkan alamat badan amil, total nominal uang dan total bobot beras. Kemudian menjelaskan terdapat form mustahiq kemudian terdapat form presentase uang dan beras berdasarkan pembagian untuk mustahiq dan fisabilillah. 


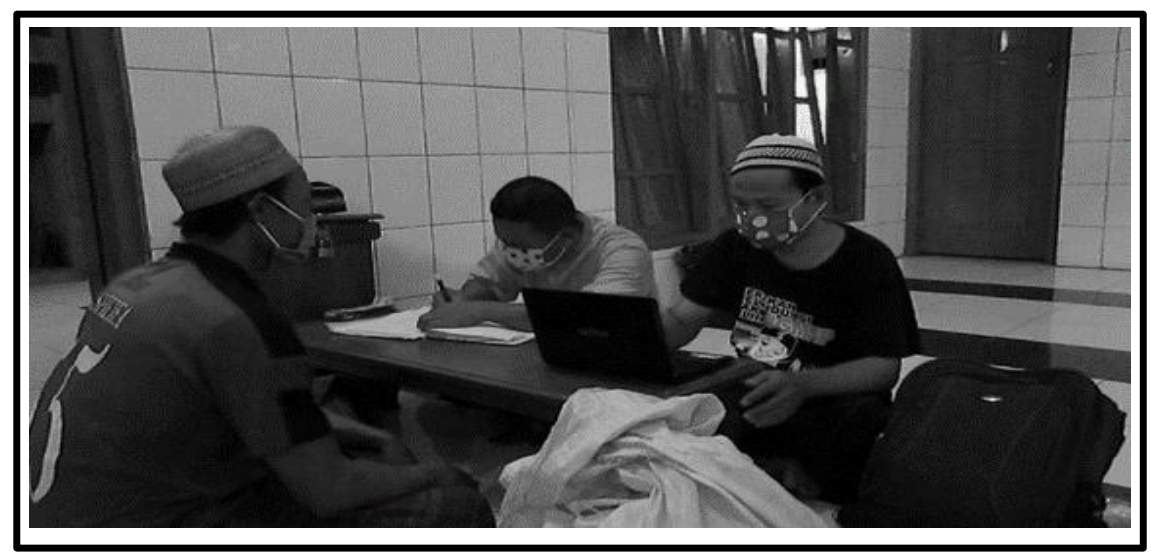

Gambar 4. Badan Amil Zakat Melakukan Input Data

Berdasarkan Gambar 4. Badan Amil Zakat Penginputan Data, mendapatkan informasi Desa Kedunggede memiliki 6.273 penduduk dan terdapat 561 mustahiq. Hasil data badan amil dusun 1 mendapatkan total sebanyak 638 muzzaki, 174 uang 4.350 .000 dan 464 beras $1.160 \mathrm{~kg}$. Dusun 2 mendapatkan total 859 muzzaki, 389 uang 9.725 .000 dan 470 beras $1.175 \mathrm{~kg}$. Dusun 3 mendapatkan total 403 muzzaki, 78 uang 1.950 .000 dan 325 beras $812,5 \mathrm{~kg}$. Berdasarkan data dusun 1 sampai dengan dusun 3 mendapatkan sebesar Rp. 16.025.000 dan 3.147,5 Kg beras dan total mustahiq sebanyak 561 penduduk. Berdasarkan perhitungan E-Zakat, hasil yang didapatkan setiap mustahiq adalah uang tunai Rp. 25.000 dan $5 \mathrm{Kg}$ beras, sedangkan untuk zakat fitrah bagi masing-masing fisabilillah sebesar Rp 250.000 dan bobot beras kurang lebih $42 \mathrm{~kg}$.

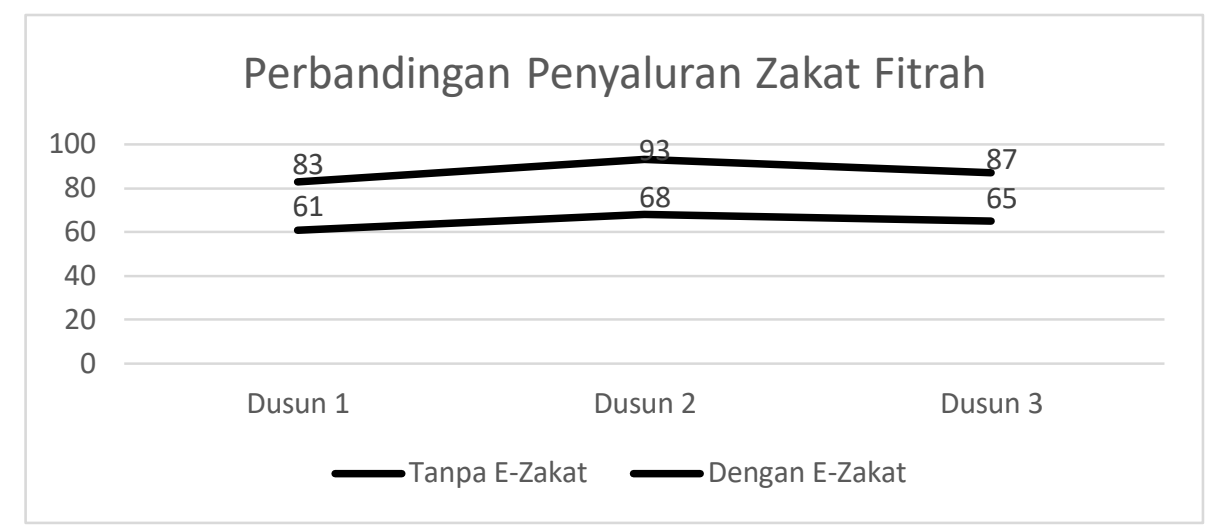

Gambar 5. Hasil Efektifitas Penyalursan Zakat Fitrah

Berdasarkan Gambar 5. Hasil Efektifitas Penyaluran Zakat Fitrah, menjelaskan bahwa penyaluran hasil zakat sebelum menggunakan fitur E-Zakat Dusun 1 sebesar 61\%, Dusun 2 sebesar 68\% dan Dusun 3 sebesar 65\%. Setelah mengikuti pelatihan dan memanfaatkan fitur E-Zakat Dusun 1 sebesar 83\%, Dusun 2 sebesar 93\% dan Dusun 3 sebesar $87 \%$.

Penelitian lain yang relevan dengan kegiatan Amikom Mitra Masyarakat seperti menghasilkan penggunaan aplikasi dapat menyimpan data dan menghitung secara automatis oleh sistem sehingga para panitia amil zakat tidak perlu menghitung secara konvensional. Kekurangannya adalah terjadi kesalahan pada aplikasi saat tidak mengisi filed data terlebih dahulu dan dibatasi sebanyak 12 kali penyimpanan data setiap harinya [6]. Penelitian kedua aplikasi dapat dijalankan pada perangkat android minimal versi

Android 7.0 Nougat yang mengakibatkan pengguna harus memiliki jenis smartphone terbaru untuk menjalankan aplikasi tersebut [7]. Penelitian ketiga membuktikan aplikasi zakat fitrah data membantu setiap orang untuk melaksanakan kegiatan zakatnya baik zakat fitrah, zakat maal, zakat profesi dan fidyah [8]. 


\section{PENUTUP}

\section{Simpulan}

Berdasarkan dari kegiatan pengabdian masyarakat yang telah dilakukan, terdapat beberapa kesimpulan yang diperoleh yaitu berdasarkan pelaksanaan kegiatan yang telah dilakukan, bahwa penggunaan teknologi informasi yaitu Aplikasi Tuan Desa dengan Fitur E-Zakat dalam pelaksanaan penginputan data zakat sangatlah efektif bagi para Badan Amil Zakat Fitrah di Desa Kedunggede. Kegiatan ini berhasil meningkatkan efisiensi waktu dan mempercepat pembagian zakat kepada mustahiq, hal ini juga di dukung oleh para Badan Amil Zakat Fitrah yang antusias dalam kegiatan pengabdian ini. Badan Amil Zakat Fitrah juga mendapatkan ilmu dari bidang teknologi yaitu mampu mengoperasian E-Zakat dari awal sampai memberikan data siapa saja yang akan menerima zakat hingga perhitungan pembagian zakat oleh E-Zakat secara merata.

\section{Saran}

Saran yang bisa disampaikan setelah kegiatan Amikom Mitra Masyarakat yang dilaksanakan pada Badan Amil Zakat Fitrah di Desa Kedunggede adalah terdapat dibeberapa lokasi atau spot yang belum didukungnya akses sinyal yang cepat.

\section{Ucapan Terima Kasih}

Penulis mengucapkan terimakasih kepada Universitas Amikom Purwokerto yang telah mendanai Skim Amikom Mitra Masyarakat Tahun Anggaran 2020.

\section{DAFTAR PUSTAKA}

[1] C. Chodriah, "Pengelolaan Zakat FItrah Di Dusun Tukang Kec. Pabelan Dalam Tinjauan Undang-Undang No 23 Tahun 2011 Tentang Pengelolaan Zakat,” Intitut Agama Islam Negeri, 2016.

[2] I. U. Safitri, "Problematika Zakat Fitrah," Tazkiya, J. Keislam. Kemasyarakatan Kebud., vol. 19 No. 1, 2018.

[3] E. S. Bastiar, Yandi., dan., Bahri, "Model Pengukuran Kinerja Lembaga Zakat Di Indonesia," Zakat dan Wakaf, vol. 6 No. 1, 2019.

[4] N. D. Firmansyah, Eka Kurnia., dan., Putrisari, "Sistem Religi dan Kepercayaan Masyarakat Kampung Adat Kuta Kecamatan Tambaksari Kabupaten Ciamis," Pengabdi. Kpd. Masy., vol. 1, pp. 236-243, 2018.

[5] Shobirin, "Teknik Pengelolaan Zakat Profesi," Zakat dan Wakaf, vol. 2 No. 2, 2015.

[6] H. P. Ramadan, "Aplikasi Perhitungan dan Pencatatan Zakat Sesuai Nisab dan Haul," Universitas Islam Indonesia, 2018.

[7] H. Mirtasari, Desiana., dan., Februariyanti, "Perhitungan Zakat Harta dan Zakat Profesi Berbasis Android," Seminar Nasional Teknologi Informasi Dan Aplikasi Komputer, Semarang, Nov. 2018.

[8] M. Syakirin, "Perancangan Aplikasi Perhitungan dan Pembayaran Zakat Berbasis Android Di Yayasan Lazis Amaliah Astra,” AMIK BSI, 2016. 